\title{
KEGIATAN MAHASISWA UNIVERSITAS MUHAMMADIYAH PURWOKERTO PESERTA KKN TERPADU DI PERPUSTAKAAN SEKOLAH DI WILAYAH KABUPATEN BANYUMAS
}

\author{
Oleh : \\ Daryanto dan Riski Febriansah*
}

\section{ABSTRACT}

This research is aimed to find out the kinds of students' contribution at some schools' libraries. This research was done Public Service Unit of Muhammadiyah University from March - May 2007. The method used in this research is by analysing the documents as the final report of Public Field Work. Based on the result of the research, it can be concluded that the students' contributions can be both technical and financial aids. The technical aids, such as: room management, inventarization, classification, catalogue, making book card, making member card, putting the book label, giving the book cover, putting the data in computer, book shelfing, arranging the wall paper an doing the administration as well as circulation service. The financial aid was Rp. 3,134,850 used tu buy the libraries' needs, including books, bookselves, paint and writing utensils.

Key words: shools' libraries.

\footnotetext{
* Dosen Tetap Jurusan Bahasa \& Sastra UNSOED
}

\section{PENDAHULUAN}

Untuk membangun perpustakaan di sekolah memang diperlukan program serta kebijakan yang jelas dari pimpinan sekolah. Salah satu yang dapat dilakukan adalah kerjasama dengan instansi lain. Dengan adanya kerjasama tersebut diharapkan dapat diperoleh keuntungan materil maupun non materil.

Kondisi perpustakaan sekolah di Kabupaten Banyumas saat ini sebagaian besar masih perlu dibenahi. Hal ini berarti banyak sekolah yang tidak mempunyai ruangan khusus untuk perpustakaan dan koleksinya tidak diolah. Semua ini disebabkan oleh tidak adanya tenaga khusus pengelola perpustakaan. Berikut ini adalah satu contoh kondisi pengelola perpustakaan sekolah di salah satu wilayah kecamatan di Kabupaten Banyumas. Menurut Taryono, seorang guru dan pengurus PGRI di Kecamatan Sumbang, bahwa di wilayah Kecamatan Sumbang terdapat 45 sekolah dasar negeri termasuk madrasah ibtidaiyah (MI), tidak mempunyai tenaga pengelola perpustakaan.
Tugas menggalaknan perpustakaan sekolah selama ini diberikan kepada guru agama, dengan pertimbangan untuk menambah jam kerja. Namun dalam prakteknya perpustakaan sekolah tidak dapat berjalan sebagai mana mestinya. Hal ini disebabkan bahwa pengelola perpustakaan tersebut kursng professional. Artinya mereka tidak pernah mendapat pendidikan dan latihan di bidang perpustakaan. Selain itu pekerjaan mengelola perpustakaan oleh guru hanya merupakan tugas tambahan.

Perpustakaan sekolah agar dapat berfungsi dengan baik, perlu dikelola oleh tenaga khusus yang terlatih. Idealnya setiap perpustakaan dikelola oleh minimal 4 orang petugas, mengingat di perpustakaan ada 4 tugas pokok yang harus dikerjakan. Keempat tugas tersebut adalah mengumpulkan, mengolah, menyimpan, dan menyebarluaskan informasi. Dimana cara melaksanakan keempat tugas tersebut memerlukan aturan tertentu. Untuk memperoleh hasil yang maksimal, tidak mungkin keempat tugas tersebut dilaksanakan hanya oleh satu orang saja. 
Dari uraian di atas diketahui bahwa pemasalahan yang timbul dalam pengelolaan perpustakaan sekolah adalah kurangnya tenaga pengelola perpustakaan yang dapat berakibat terhadap jalannya perpustakan sekolah.

Tujuan utama dari penelitian ini adalah untuk mengetahui kegiatan apa saja yang dilakukan mahasiswa Universitas Muhammadiyah Purwokerto peserta KKN Terpadu dalam Program Bina Sekolah di wilayah kabupaten Banyumas.

\section{METODE PENELITIAN}

Penelitian ini dilakukan di Fakultas Kependidikan dan Lembaga Pengabdian Pada Masyarakat (LPPM) Universitas Muhammadiyah Purwokerto pada bulan Maret sampai dengan Mei 2007.

Sumber data penelitian ini adalah data sekunder yang bersumber dari Laporan KKN dan dokumen lain yang ada hubungannya dengan pokok permasalahan. Dokumen tersebut, (1) Laporan Hasil KKN, (2) Makalah Pembekalan KKN, dan ( 3) Buku Pedoman KKN. Selain data sekundar, peneliti juga mencari data pelengkap yang diperoleh dari wawancara dengan pihak LPPM dan juga survei ke perpustakaan salah satu sekolah yang digunakan untuk kegiatan KKN.

Analisis yang dipergunakan adalah data yang relevan dijabarkan dan ditabulasi, kemudian dianalisis dengan metode kualitatif, yaitu menguraikan data berdasarkan pada prinsip-prinsip ilmu perpustakaan, dokumentasi dan informasi.

\section{HASIL DAN PEMBAHASAN}

\section{Isi materi pembekalan KKN - PPL Terpadu.}

Sebelum mahasiswa melaksanakan kegiatan KKN-PPL Terpadu, terlebih dahulu harus mengikuti kegiatan pembekalan. Materi pembekalan dibagi dalam 2 kelompok yaitu pembekalan 1 dan pembekalan 2. Dalam pembekalan 1 diberikan materi khusus kerokhanian dan etika. Sedangkan dalam pembekalan 2 diberikan materi yang bersifat pengembangan wawasan dan teknis operasional (Yulianto, 2006 : 10-12). Materi pembekalan untuk bina perpustakaan sekolah termasuk dalam kelompok pembekalan 2 .

Dalam materi bina perpustakaan sekolah, disampaikan tentang jenis tugas yang ada di perpustakaan dan bagaimana mengelola koleksi mulai dari mendaftar buku, mengelompokkan dan membuat kartu katalog. Tugas mengolah koleksi antara lain, adalah mengelompokkan berdasar isi, membuat alat telusur, serta memberikan tanda serta perlengkapan lain, seperti katalog, label, sampul, kantong buku, kartu buku dan tanggal kembali. Semua ini harus dikerjakan agar koleksi yang dimiliki dapat disimpan dan dapat ditemukan kembali dengan cepat untuk dimanfaatkan.

Itulah isi dari materi pembekalan tentang kegiatan yang harus dikerjakan oleh tenaga perpustakaan. Dengan materi ini diharapkan para mahasiswa peserta KKN setelah terjun di sekolah tidak menghadapi kebingungan. Sasaran dari kegiatan KKN-PPL Terpadu pada tahun 2006 ini adalah bina sekolah. Dalam bina sekolah ada 4 bidang yang menjadi tempat kegiatan peserta KKN-PPL. Keempat bidang tersebut, yaitu, (1) Pembelajaran, (2) Laboratorium, (3) Ekstra Kurikuler, dan (4) Perpustakaan.

Penelitian ini akan membahas tentang kegiatan mahasiswa di perpustakaan sekolah. Sasaran dari kegiatan bina perpustakaan adalah perbaikan manajemen perpustakaan, baik sekolah yang belum mempunyai perpustakaan maupun yang sudah mempunyai perpustakaan. Tabel 1 berikut ini menjelaskan wilayah dan nama sekolah yang dijadikan kegiatan KKN-PPL. Dari Tabel 1 diketahui bahwa jumlah perpustakaan sekolah yang dibina ada 29 sekolah baik negeri maupun swasta yang tersebar di 8 wilayah kecamatan yang ada di Kabupaten Banyumas. Berdasar tingkat sekolah ada 44,83 $\%$ perpustakaan sekolah lanjutan tingkat pertama, dan $55,17 \%$ merupakan perpustakaan sekolah lanjutan tingkat atas.

Jadi dapat dikatakan bahwa yang mendapat bantuan pembinaan perpustakaan lebih banyak di perpustakaan sekolah tingkat atas dibanding perpustakaan sekolah menengah pertama. 
Tabel 1. Jumlah Perpustakaan Sekolah Yang Dibina berdasar Wilayah

\begin{tabular}{|c|c|c|c|c|c|c|}
\hline \multirow[b]{2}{*}{ No } & \multirow[b]{2}{*}{ Wilayah Kec. } & \multirow[b]{2}{*}{ Nama Sekolah } & \multicolumn{2}{|c|}{ Tingkat } & \multicolumn{2}{|c|}{ Total } \\
\hline & & & $\begin{array}{l}\text { SLTP } \\
(\%) \\
\end{array}$ & $\begin{array}{c}\text { SLTA } \\
(\%)\end{array}$ & $\mathrm{Jml}$ & $\%$ \\
\hline 1 & $\begin{array}{l}\text { Purwokerto } \\
\text { Barat }\end{array}$ & $\begin{array}{l}\text { 1. SMK Wiworotomo Pwt } \\
\text { 2. SMK Muh. } 1 \text { Pwt } \\
\text { 3. SMK 75-1 Pwt } \\
\text { 4. SMK 75-2 Pwt } \\
\text { 5. SMP Gunungjati } 1\end{array}$ & $\begin{array}{l}- \\
- \\
- \\
\text { v }\end{array}$ & $\begin{array}{l}v \\
v \\
v \\
v \\
-\end{array}$ & 5 & 17,24 \\
\hline 2 & $\begin{array}{l}\text { Purwokerto } \\
\text { Selatan }\end{array}$ & $\begin{array}{l}\text { 1. SMK Swagaya } 2 \text { Pwt } \\
\text { 2. SMK Muh. } 3 P_{w t} \\
\text { 3. SMP Muh. } 2 P_{w t} \\
\text { 4. SMP Muh. 1 Pwt }\end{array}$ & $\begin{array}{l}- \\
v \\
v\end{array}$ & $\begin{array}{l}v \\
v \\
- \\
-\end{array}$ & 4 & 13,80 \\
\hline 3 & $\begin{array}{l}\text { Purwokerto } \\
\text { Utara }\end{array}$ & $\begin{array}{l}\text { 1. SMP Muh } 3 \text { Pwt } \\
\text { 2. SMK Swagaya I Pwt } \\
\text { 3. SMK Kesatrian Pwt }\end{array}$ & $\begin{array}{l}v \\
- \\
-\end{array}$ & $\begin{array}{l}- \\
v \\
v\end{array}$ & 3 & 10,34 \\
\hline 4 & $\begin{array}{l}\text { Purwokerto } \\
\text { Timur }\end{array}$ & $\begin{array}{l}\text { 1. MAN } 1 \text { Pwt } \\
\text { 2. MAN } 2 \text { Pwt } \\
\text { 3. SMK Bhakti Pwt }\end{array}$ & $\begin{array}{l}- \\
-\end{array}$ & $\begin{array}{l}\mathrm{v} \\
\mathrm{v} \\
\mathrm{v}\end{array}$ & 3 & 10,34 \\
\hline 5 & Ajibarang & $\begin{array}{l}\text { 1. SMK Muh.l Ajibarang } \\
\text { 2. SMK Muh. } 2 \text { Ajibarang } \\
\text { 3. SMA Negri Ajibarang } \\
\text { 4. SMP Negeri } 3 \text { Ajibarang } \\
\text { 5. SMP Muh. Ajibarang }\end{array}$ & $\begin{array}{l}- \\
- \\
- \\
\mathrm{v} \\
\mathrm{v}\end{array}$ & $\begin{array}{l}\mathrm{v} \\
\mathrm{v} \\
\mathrm{v} \\
- \\
-\end{array}$ & 5 & 17,24 \\
\hline 6 & Sokaraja & $\begin{array}{l}\text { 1. SMA Negeri Sokaraja } \\
\text { 2. SMP Negeri } 2 \text { Sokaraja } \\
\text { 3. SMP Muh. Sokaraja } \\
\text { 4. SMP Negeri } 3 \text { Sokaraja }\end{array}$ & $\begin{array}{l}- \\
\mathrm{v} \\
\mathrm{v} \\
\mathrm{v}\end{array}$ & $\begin{array}{l}v \\
- \\
- \\
-\end{array}$ & 4 & 13,80 \\
\hline 7 & Patikraja & $\begin{array}{l}\text { 1. MTS Muh. Patikraja } \\
\text { 2. SMP Negeri I Patikraja }\end{array}$ & $\begin{array}{l}\mathrm{v} \\
\mathrm{v}\end{array}$ & $\begin{array}{l}- \\
-\end{array}$ & 2 & 6,90 \\
\hline 8 & Rawalo & $\begin{array}{l}\text { 1. SMP Muh. Rawalo } \\
\text { 2. SMP Negeri I Rawalo } \\
\text { 3. SMA Negeri } 1 \text { Rawalo }\end{array}$ & $\begin{array}{l}\mathrm{v} \\
\mathrm{v} \\
- \\
\end{array}$ & $\begin{array}{l}- \\
- \\
\mathrm{v}\end{array}$ & 3 & 10,34 \\
\hline $\mathbf{J m l}$ & 8 & & $\begin{array}{c}1 \mathbf{1 3} \\
(44,83 \%)\end{array}$ & $\begin{array}{c}\mathbf{1 6} \\
(55,17 \%)\end{array}$ & 29 & $100 \%$ \\
\hline
\end{tabular}

Sumber : Data Th. 2006 di Bag. Pendidikan setelah diolah.

Berdasarkan penyebaran jumlah perpustakaan sekolah yang dibina, ternyata jumlah terbanyak $(17,24 \%)$ terdapat di wilayah Purwokerto Barat dan Ajibarang, sedangkan jumlah paling sedikit di wilayah Kecamatan Patikraja $(6,90 \%)$. Hal ini berarti bahwa penyebaran jumlah perpustakaan sekolah yang mendapat bantuan pembinaan belum merata.

Pada tahun 2005/2006 periode semester genap, UMP menyelenggarakan KKN Alternatif, dimana lokasinya pada sekolah-sekolah di wilayah kabupaten Banyumas. Pada saat itu jumlah sekolah yang digunakan untuk kegiatan KKN Alternatif sebanyak 41 sekolah dari SD SLTA, yang tersebar di 7 kecamatan. Menurut staf di LPPM UMP, bahwa kegiatan program
KKN setiap tahun dilaksanakan di sekolahsekolah yang belum pernah dipakai untuk kegiatan KKN. Tujuannya adalah agar kegiatan KKN di sekolah dapat dilaksanakan secara merata. Hal ini jangan sampai terjadi ada suatu sekolah yang dijadikan untuk tempat kegiatan KKN sampai dua kali. Jumlah sekolah yang terdapat di wilayah Kabupaten Banyumas sebanyak 1324 sekolah dari SD - SLTA, baik negeri maupun swasta.

Dari dua program KKN yang dilaksanakan oleh UMP tersebut $\mathrm{di}$ atas, diketahui bahwa antara tahun 2005/2006 dan 2006/2007 sudah 70 sekolah yang digunakan sebagai tempat KKN. Jadi setiap tahun rata-rata ada 35 sekolah yang digunakan untuk kegiatan KKN. Dengan demikian untuk melaksanakan 
KKN yang sejenis di sekolah di wilayah Banyumas perlu waktu ( $1324: 30$ ) minimal 44 kali program kegiatan $\mathrm{KKN}$.

\section{Jenis Kegiatan Yang Dilaksanakan di Perpustakaan}

Kegiatan yang dilaksanakan oleh peserta KKN-PPL di setiap sekolah berbeda. Hal ini disebabkan oleh kondisi perpustakaan, jumlah peserta dan kegiatan lain di lokasi tersebut. Kondisi perpustakaan yang dimaksud antara lain adalah ruangan, koleksi dan peralatan. dilaksanakan oleh peserta KKN-PPL pada setiap Perpustakaan Sekolah, seperti pada Tabel 2

Berdasarkan tabel 2 diketahui bahwa jenis kegiatan yang dilaksanakan peserta $\mathrm{KKN}$ di perpustakaan sekolah dapat dikelompokan menjadi 12 yaitu, (a) tata ruang, (b) inventarisasi, (c) klasifikasi, (d) katalogisasi, (e) membuat kartu buku, (f) membuat kartu anggota, (g) membuat label buku, (h) memasang sampul buku, (i) masukan data ke komputer, (j) pengerakan, (k) menyusun majalah dinding, dan (l) melakukan administrasi \& layanan sirkulasi.

Tabel 2. Jenis Kegiatan Yang Dilaksanakan Di Perpustakaan Sekolah.

\begin{tabular}{|c|c|c|c|c|c|c|c|c|c|c|c|c|}
\hline \multirow[t]{2}{*}{ NO. \& NAMA SEKOLAH } & \multicolumn{12}{|c|}{ JENIS KEGIATAN } \\
\hline & A & B & $\mathrm{C}$ & D & $\mathrm{E}$ & $\mathrm{F}$ & G & $\mathrm{H}$ & I & $\mathrm{J}$ & $\mathrm{K}$ & $\mathrm{L}$ \\
\hline 1. SMP Muh 2 Pwt & $\mathrm{V}$ & V & $\mathrm{V}$ & $\mathrm{V}$ & - & - & $\mathrm{V}$ & - & - & $\mathrm{V}$ & - & - \\
\hline 2. MAN 1 Pwt & - & $\mathrm{V}$ & $\mathrm{V}$ & - & - & - & $\mathrm{V}$ & - & - & $\mathrm{V}$ & - & - \\
\hline 3. SMK Muh 3 Pwt & $\mathrm{V}$ & $\mathrm{V}$ & $\mathrm{V}$ & $\mathrm{V}$ & F & - & - & - & - & $\mathrm{V}$ & - & - \\
\hline 4. SMP Muh 3 Pwt & $\mathrm{V}$ & - & - & - & - & - & - & $\mathrm{V}$ & - & - & $\mathrm{V}$ & $\mathrm{V}$ \\
\hline 5. SMP Negeri Patikraja & $\mathrm{V}$ & - & - & - & - & - & - & - & - & $=$ & $\mathrm{V}$ & - \\
\hline 6. SMK 75-2 Pwt & $\mathrm{V}$ & $\mathrm{V}$ & - & $\mathrm{V}$ & $\mathrm{V}$ & - & $\mathrm{V}$ & $\mathrm{V}$ & - & - & $\mathrm{V}$ & - \\
\hline 7. SMP Muh Ajibarang & $\mathrm{V}$ & $\mathrm{V}$ & $\mathrm{V}$ & $\mathrm{V}$ & - & - & $\mathrm{V}$ & - & - & - & - & - \\
\hline 8. SMK Muh 2 Ajibarang & $\mathrm{V}$ & $\mathrm{V}$ & $\mathrm{V}$ & - & - & - & $\mathrm{V}$ & $\mathrm{V}$ & - & $\mathrm{V}$ & - & $=$ \\
\hline 9. SMK Muh 2 Ajibarang & $\dot{v}$ & $\mathrm{~V}$ & $\mathrm{~V}$ & - & - & - & - & - & - & - & - & - \\
\hline 10. SMA Negeri 1 Rawalo & $\mathrm{V}$ & $\mathrm{V}$ & $\mathrm{V}$ & - & - & - & - & - & - & - & - & - \\
\hline 11. SMK Swagaya $2 \mathrm{Pwt}$ & - & $\mathrm{V}$ & - & - & - & $\bar{V}$ & - & - & - & $\mathrm{V}$ & - & $\mathrm{V}$ \\
\hline 12. SMP Gunungjati 1 Pwt & - & - & $\mathrm{V}$ & $\mathrm{V}$ & - & - & - & V & - & V & $\mathrm{V}$ & - \\
\hline 13. SMK Swagaya Pwt & - & - & - & - & - & - & - & $\mathrm{V}$ & - & $\mathrm{V}$ & $\mathrm{V}$ & $\mathrm{V}$ \\
\hline 14. MTs Patikraja & $\mathrm{V}$ & - & - & $=$ & - & - & $\mathrm{V}$ & - & - & $\mathrm{V}$ & - & $\mathrm{V}$ \\
\hline 15. SMP Muh Rawalo & $\mathrm{V}$ & $\mathrm{V}$ & $\mathrm{V}$ & $\mathrm{V}$ & $\overline{\mathrm{V}}$ & $\mathrm{v}$ & $\bar{v}$ & $\mathrm{~V}$ & $\mathrm{~V}$ & $\mathrm{~V}$ & $\mathrm{~V}$ & $\mathrm{~V}$ \\
\hline 16.SMP N Ajibarang & $\mathrm{V}$ & - & $\mathrm{V}$ & - & - & - & $\mathrm{V}$ & - & - & - & - & $\bar{V}$ \\
\hline $\mathrm{Jml}$ & 12 & 10 & 10 & 6 & 2 & 2 & 8 & 6 & 1 & 9 & 6 & 6 \\
\hline$\%$ & 75 & 62,5 & 62,5 & 37,5 & 12,5 & 12 , & 50 & 375 & 6,25 & 56,2 & 37,5 & 37,5 \\
\hline
\end{tabular}

Ruangan perpustakaan di beberapa sekolah difungsikan sebagai gudang atau tempat penyimpanan barang-barang kantor. Untuk itu perlu dibersihkan, dicat dan ditata sehingga ruangan tersebut menjadi tempat yang nyaman untuk kegiatan perpustakaan.

Keadaan koleksi di perpustakaan juga bermacam-macam, baik jumlah maupun kelengkapannya. Sebagian ada yang masih utuh belum diproses, sehingga perlu diproses dari awal hingga buku dapat dipinjamkan ke pengguna. Berikut ini jenis kegiatan yang
Jumlah jenis kegiatan yang dilaksanakan peserta KKN Terpadu di perpustakaan sekolah minimal ada 3 dan maksimal 12 kegiatan. Jumlah 3 jenis kegiatan dilaksanakan di perpustakaan SMP Negeri Patikraja, dan 12 jenis kegiatan dilaksanakan di perpustakaan SMP Muhammadiyah Purwokerto.

Berdasar jenis kegiatannya ternyata $62,5 \%-75 \%(10-12)$ sekolah mendapat bantuan kegiatan tata ruang, inventarisasi dan klasifikasi. Dalam mengatur tata ruang ada kegiatan membersihkan, mengecat dinding serta menata perabot di dalam ruangan. Kemudian 
dalam kegiatan inventarisasi, mahasiswa mendaftar atau mencatat koleksi terutama bukubuku ke dalam buku induk. Selain kedua kegiatan tsb. di atas, kegiatan yang cukup menguras pikiran adalah kegiatan klasifikasi. Tujuan dari kegiatan klasifikasi adalah mengelompokkan buku berdasarkan isi atau ilmunya.

Sedangkan kegiatan lain yang cukup banyak dikerjakan oleh peserta $\mathrm{KKN}$, adalah membuat dan memasang label atau kode buku serta pengerakan, ada lebih dari $50 \%$ perpustakaan sekolah.
Pendidikan. Pada tabel 3 berikut ini adalah penyebaran peserta KKN - PPL Terpadu pada sekolah yang ada di kabupaten Banyumas.

Berdasarkan Tabel 3 dapat diketahui bahwa jumlah mahasiswa yang melakukan kegiatan di 16 sekolah sebanyak 162 orang, terdiri dari 32 orang $(19,75 \%)$ dari jurusan Pendidikan Bahasa Indonesia, dan 130 orang $(80,25 \%)$ dari jurusan lain pada FKIP UMP. Dalam setiap sekolah minimal terdapat satu orang dan maksimal ada 4 orang dari Jurusan Pendidikan Bahasa Indonesia.

Tabel 3. Jumlah Peserta KKN-PPL Berdasarkan Nama Sekolah

\begin{tabular}{|l|l|c|c|c|c|}
\hline \multirow{2}{*}{ No } & \multirow{2}{*}{ Nama Sekolah } & \multicolumn{2}{|c|}{ Jumlah Mhs } & \multirow{2}{*}{ Total } & \multirow{2}{*}{ Ket } \\
\cline { 3 - 4 } & & Indo & Lain & & \\
\hline 1 & SMP Muh 2 Pwt & 2 & 8 & 10 & \\
\hline 2 & MAN 1 Pwt & 1 & 8 & 9 & \\
\hline 3 & SMK Muh 3 Pwt & 2 & 8 & 10 & \\
\hline 4 & SMP Muh 3 Pwt & 1 & 12 & 13 & \\
\hline 5 & SMP Negeri 1 Patikraja & 2 & 9 & 13 & \\
\hline 6 & SMK 75-2 Pwt & 2 & 8 & 10 & \\
\hline 7 & SMP Muh Ajibarang & 1 & 10 & 11 & \\
\hline 8 & SMA Muh 1 Pwt & 2 & 9 & 11 & \\
\hline 9 & SMK Muh 2 Ajibarang & 4 & 7 & 11 & \\
\hline 10 & SMA Negeri 1 Rawalo & 2 & 13 & 15 & \\
\hline 11 & SMK Swagaya 2 Pwt & 3 & 3 & 6 & \\
\hline 12 & SMP Gunungjati 1 Pwt & 2 & 7 & 9 & \\
\hline 13 & SMK Swagaya 1 Pwt & 2 & 3 & 5 & \\
\hline 14 & MTS Muh Patikraja & 2 & 8 & 10 & \\
\hline 15 & SMP Muh Rawalo & 2 & 7 & 9 & \\
\hline 16 & SMP Negeri Ajibarang & 2 & 10 & 12 & \\
\hline & Jumlah : & $\mathbf{3 2}$ & $\mathbf{1 3 0}$ & 162 & \\
\hline & \% & 19,75 & 80,25 & 100 & \\
\hline
\end{tabular}

Sumber : Dokumen laporan Hasil KKN setelah diolah.

Yang menarik adalah sudah ada satu sekolah yang melakukan pemasukan data ke komputer. Hal ini menandakan bahwa mereka telah memanfaatkan media teknologi yang mutakhir untuk kegiatan di perpustakaan

\section{Jumlah peserta KKN-PPL yang bertugas di Perpustakaan}

Pada tahun 2006 semester genap jumlah mahasiswa UMP yang mendaftar sebagai peserta KKN - PPL Terpadu berjumlah 162 orang. Mereka adalah mahasiswa dari Fakultas
Komposisi pembagian seperti ini cukup baik, sebab di dalam setiap kelompok terdapat mahasiswa dari Jurusan Pendidikan Bahasa Indonesia.

Mahasiswa Jurusan Pendidikan Bahasa Indonesia mempunyai bekal ketrampilan bidang manajemen perpustakaan lebih baik dibandingkan mahasiswa jurusan lain. Sebab mahasiswa jurusan Pendidikan Bahasa Indonesia telah mengikuti mata kuliah wajib Pengantar Ilmu Perpustakaan pada semester awal. 


\section{Sumbangan Dana}

Tabel 4. Jumlah Dana Yang Disumbangkan Untuk Kegiatan di Perpustakaan Sekolah

\begin{tabular}{|c|c|c|c|c|c|}
\hline \multirow[t]{2}{*}{ No } & \multirow[t]{2}{*}{ Nama Sekolah } & \multirow{2}{*}{$\begin{array}{c}\text { Dana Yang } \\
\text { Terkumpul (Rp) }\end{array}$} & \multicolumn{2}{|c|}{$\begin{array}{c}\text { Penggunaan Dana Untuk } \\
\text { Kegiatan }\end{array}$} & \multirow{2}{*}{$\begin{array}{c}\text { Jenis } \\
\text { Pengeluaran }\end{array}$} \\
\hline & & & $\begin{array}{l}\text { Perpust } \\
(\mathrm{Rp} / \%)\end{array}$ & $\begin{array}{c}\text { Lain } \\
(\mathrm{Rp} / \%)\end{array}$ & \\
\hline 1 & SMP Muh 2 Pwt & $1.991 .000,00$ & $\begin{array}{l}843.500,00 \\
(42,36 \%)\end{array}$ & $\begin{array}{l}1.147 .500,00 \\
(57,64 \%)\end{array}$ & \multirow{16}{*}{$\begin{array}{l}\text { 1. Membeli buku } \\
\text { 2. Membuat rak buku } \\
\text { 3. Kertas } \\
\text { 4. Spidol } \\
\text { 5. Gunting } \\
\text { 6. Pita Ketik } \\
\text { 7. Isolasi } \\
\text { 8. Transpot } \\
\text { 9. Sampul buku } \\
\text { 10. Cat }\end{array}$} \\
\hline 2 & MAN 1 Pwt & $1.278 .500,00$ & $\begin{array}{l}447.950,00 \\
(35,04 \%)\end{array}$ & $\begin{array}{l}330.550,00 \\
(64,96 \%)\end{array}$ & \\
\hline 3 & SMK Muh 3 Pwt & $1.615 .000,00$ & $\begin{array}{l}146.700,00 \\
(9,08 \%)\end{array}$ & $\begin{array}{l}1.468 .300 \\
(90,92 \%)\end{array}$ & \\
\hline 4 & SMP Muh 3 Pwt & $1.735 .000,00$ & $\begin{array}{l}155.000,00 \\
(8,93 \%)\end{array}$ & $\begin{array}{l}1.580 .000 \\
(91,07 \%)\end{array}$ & \\
\hline 5 & SMP Negeri 1 Patikraja & $1.501 .500,00$ & $?(0 \%)$ & $\begin{array}{l}1.501,00 \\
(100 \%)\end{array}$ & \\
\hline 6 & SMK 75-2 Pwt & $1.765 .000,00$ & $\begin{array}{l}29.150,00 \\
(1,65 \%)\end{array}$ & $\begin{array}{l}1.735 .850,00 \\
(98,35 \%)\end{array}$ & \\
\hline 7 & SMP Muh Ajibarang & $1.517 .500,00$ & $\begin{array}{l}598.500,00 \\
(39,44 \%)\end{array}$ & $\begin{array}{l}919.000,00 \\
60,56 \%\end{array}$ & \\
\hline 8 & SMA Muh I Pwt & $897.000,00$ & $\begin{array}{l}243.000,00 \\
(27,09 \%)\end{array}$ & $\begin{array}{l}654.000,00 \\
(72,91 \%)\end{array}$ & \\
\hline 9 & SMK Muh 2 Ajibarang & $1.866 .500,00$ & $\begin{array}{l}40.000,00 \\
(2,14 \%)\end{array}$ & $\begin{array}{l}1.826 .500,00 \\
(97,86 \%)\end{array}$ & \\
\hline 10 & SMA Negerj 1 Rawalo & $3.894 .000,00$ & $\begin{array}{l}362.000,00 \\
(9,30 \%)\end{array}$ & $\begin{array}{l}3.532 .000,00 \\
(90,70 \%)\end{array}$ & \\
\hline 11 & SMK Swagaya 2 Pwt & $2.187 .500,00$ & $\begin{array}{l}106.500,00 \\
(4,87 \%)\end{array}$ & $\begin{array}{l}2.081 .000,00 \\
(95,13 \%)\end{array}$ & \\
\hline 12 & SMP Gunungjati 1 Pwt & $1.093 .000,00$ & $\begin{array}{l}203.750,00 \\
(18,64 \%)\end{array}$ & $\begin{array}{l}889.250,00 \\
(81,36 \%)\end{array}$ & \\
\hline 13 & SMK Swagaya I Pwt & $757.000,00$ & $\begin{array}{l}46.000,00 \\
(6,08 \%)\end{array}$ & $\begin{array}{l}711.000,00 \\
(93,92 \%)\end{array}$ & \\
\hline 14 & MTS Muh Patikraja & $2.010 .000,00$ & $\begin{array}{l}316.000,00 \\
(15,72 \%)\end{array}$ & $\begin{array}{l}1.694 .000,00 \\
(84,28 \%)\end{array}$ & \\
\hline 15 & SMP Muh Rawalo & $1.781 .300,00$ & $\begin{array}{l}340.100,00 \\
(19,09 \%)\end{array}$ & $\begin{array}{l}1.441 .200,00 \\
(80,91 \%)\end{array}$ & \\
\hline \multirow[t]{2}{*}{16} & SMP Negeri Ajibarang & $1.324 .000,00$ & $?(0 \%)$ & $\begin{array}{l}1.324 .000,00 \\
(100 \%)\end{array}$ & \\
\hline & Jumlah : & $\begin{array}{l}24.185 .500,00 \\
(100 \%)\end{array}$ & $\begin{array}{c}3.134 .850,00 \\
(12,96 \%)\end{array}$ & $\begin{array}{c}21.05065,00 \\
(87,4 \%)\end{array}$ & \\
\hline
\end{tabular}

Sumber : Dokumen laporan Hasil KKN setelah diolah.

Selain itu sebelum melakukan KKN mereka bersama dengan jurusan lain juga mendapat materi pembekalan tentang manajemen perpustakaan sekolah.

Peserta KKN-PPL dalam melakukan kegiatannya di sekolah tidak hanya memberikan bantuan dalam bentuk tenaga dan pikiran, tetapi mereka juga memberikan bantuan dalam bentuk dana. Sumber dana tersebut diperoleh dari iuran antar anggota kelompok, bantuan dari Universitas Muhammadiyah, Bappeda serta beberapa donatur. Jumlah dana yang disumbangkan seperti tabel berikut ini. Dari tabel 4 di atas diketahui bahwa Perpustakaan SMP Muhammadiyah 2 Purwokerto mendapat bantuan dana terbesar yaitu Rp. 843.500,00 sedangkan SMK 75-2 mendapat bantuan dana yang paling kecil (Rp. 29.150,00). Tetapi secara umum dana yang dikeluarkan untuk membiayai kegiatan perpustakaan sekolah masih cukup kecil ( 12,96 $\%$ ), jika dibandingkan dengan dana yang dikeluarkan untuk kegiatan lain ( $87,4 \%$ ). Pengeluaran untuk Perpustakaan Sekolah 
meliputi, pembelian buku untuk tambahan koleksi, pembuat rak/almari, pembelian cat, serta kebutuhan alat tulis. Sedangkan pengeluaran untuk kegiatan lain antara untuk; pramuka, PMR, seni, bahasa, dan olah raga.

\section{Lama Waktu Peserta KKN-PPL bertugas di Perpustakaan}

Untuk mengetahui lama waktu yang dibutuhkan oleh peserta KKN-PPL dalam melaksanakan tugas di Perpustakaan Sekolah dapat dilihat pada Tabel 5, berikut ini.

\section{KESIMPULAN DAN SARAN}

\section{Kesimpulan}

Kegiatan Kuliah Kerja Nyata ( KKN) oleh mahasiswa ternyata dapat membantu pengembangan perpustakaan. Hal ini dapat dibuktikan dari kegiatan mahsiswa peserta $\mathrm{KKN}$ yang dilaksanakan Universitas Muhammadiyah Purwkerto (UMP). Pada tahun 2006. sejumlah 162 mahasiswa UMP peserta KKN - PPL Terpadu, telah memberikan bantuan tenaga dan dana kepada 16 Perpustakaan Sekolah di kabupaten Banyumas. Dengan bantuan tersebut paling tidak beban pekerjaan di perpustakaan sekolah menjadi berkurang.

Tabel 5.

Jumlah Waktu Yang Dibutuhkan Untuk Kegiatan di Perpustakaan Sekolah

\begin{tabular}{|l|l|c|c|}
\hline No. & \multicolumn{1}{|c|}{ NAMA SEKOLAH } & JML HARI & JML KEGIATAN \\
\hline 1 & SMP Muh 2 Pwt & 13 & 6 \\
\hline 2 & MAN 1 Pwt & 21 & 4 \\
\hline 3 & SMK Muh 3 Pwt & 6 & 5 \\
\hline 4 & SMP Muh 3 Pwt & 11 & 4 \\
\hline 5 & SMP Negeri 1 Patikraja & 6 & 2 \\
\hline 6 & SMK 75-2 Pwt & 11 & 7 \\
\hline 7 & SMP Muh Ajibarang & 19 & 5 \\
\hline 8 & SMA Muh 1 Pwt & 6 & 6 \\
\hline 9 & SMK Muh 2 Ajibarang & 14 & 3 \\
\hline 10 & SMA Negeri 1 Rawalo & 14 & 3 \\
\hline 11 & SMK Swagaya 2 Pwt & 19 & 4 \\
\hline 12 & SMP Gunungjati 1 Pwt & 5 & 5 \\
\hline 13 & SMK Swagaya 1 Pwt & 5 & 4 \\
\hline 14 & MTS Muh Patikraja & 11 & 4 \\
\hline 15 & SMP Muh Pwt & 14 & 12 \\
\hline 16 & SMP Negeri Ajibarang & 7 & 4 \\
\hline & Jumlah : & 182 & 48 \\
\hline & Rata-2 & 11,37 & 47 \\
\hline
\end{tabular}

Sumber : Dokumen Laporan KKN setelah diolah.

Dari tabel tersebut diketahui bahwa ratarata waktu yang dihabiskan oleh mahasiswa untuk melaksanakan kegiatan di perpustakaan adalah lebih dari 11 hari, dengan jumlah kegiatan rata-rata lebih dari 4 jenis kegiatan. Untuk itu selama lebih dari 11 hari di perpustakaan sekolah, mahasiswa telah cukup banyak menyumbangkan tenaganya untuk melakukan kegiatan.
Bentuk bantuan tenaga dari mahasiswa dapat dikelompokan dalam 12 kegiatan, terdiri dari yaitu; ( 1) tata ruang, (2) inventarisasi, (3) klasifikasi, (4) katalogisasi, (5) buat kartu buku, (6) buat kartu anggota, (7) pasang label buku, (8) pasang sampul buku, (9) masukan data ke komputer, (10) pengerakan, (11) menyusun majalah dinding, dan (12) mengerjakan administrasi dan layanan sirkulasi. 
Selain melakukan 12 kegiatan di atas, mahasiswa juga menyumbang dana untuk perpustakaan sekolah berjumlah Rp. 3.134.850,00. Dana tersebut digunakan untuk membeli buku, membuat rak buku, membeli cat tembok dan alat tulis.

\section{Saran}

Agar program pembinaan perpustakaan sekolah dapat lebih efektif sebaiknya pihak Universitas Muhammadiyah Purwokerto mengirimkan mahasiswa peserta $\mathrm{KKN}$ ke perpustakaan sekolah yang koleksinya belum diolah atau masih utuh, terutama perpustakaan sekolah yang ada daerah pelosok pedesaan terpencil. Tujuannya agar membantu menarik minat membaca siswa di sekolah tsb.

\section{DAFTAR PUSTAKA}

Ariningsih, Welmin Sunyi, dkk.2006."Minat dan kebiasaan membaca masyarakat Jawa Timur". Jurnal FKP2T Th.1 No. 1, hal. 3138.

Darmono. 2001. Manajemen dan tata kerja Perpustakaan Sekolah.Jakarta: Grassindo.

Daryanto. 2000. Materi Pembekalan : Cara mengelola perpustakaan sekolah. Purwokerto : Universitas Muhammadiyah Purwokerto.

Keputusan Kepala Perpustakaan Nasional R.I. Nomor 72 tahun 1999. Jakarta : Yasmin

Murgono.1999."Pembinaan perpustakaan sekolah dasar negeri se - kecamatan Semarang Selatan (kegiatan pengabdian pada masyarakat)". Media Pustakwan Vol. VI, No. 2, hal. 34-40.

Pendit, Putu Laxman. 2003. Penelitian ilmu perpustakaan dan informasi; suatu pengantar diskusi epistemologi dan metodologi. Jakarta : JIP - FS UI.

Sulistyo-Basuki.2006. "Metodologi kuantitatif dan kualitatif dalam penelitian ilmu perpustakaan dan informasi". Visi Pustaka Vol. 8 No. 1 hal. 11-21.

1992. Teknik dan jasa dokumentasi. Jakarta : Gramedia Pustaka Utama.

Supriyanto, YP.2004. "Buku dan budaya gemar membaca", Info Persadha. Vol. 2 No. 2 hal. 8-10.

Susanto, Yohanes Edi. 2005. "Revitalisasi fungsi perpustakaan dalam pedagogi bervisi kecerdasan masyarakat". Info Persadha, vol. 3 No. 1 hal. 2-7.

Zen, Kentjanawati Hasan. 2004."Faktor-faktor penyebab menurunnya pemanfaatan perpustakaan di desa Muara Enim (hasil penelitian)". Jurnal Kepustakawanan dan Masyarakat Membaca, XX, (1) hal. 21-26. 